\title{
Perturbation of sheep ovarian surface epithelial cells by ovulation: evidence for roles of progesterone and poly(ADP-ribose) polymerase in the restoration of DNA integrity
}

\author{
W J Murdoch \\ Reproductive Biology Program and Department of Animal Science, University of Wyoming, Laramie, Wyoming 82071, USA \\ (Requests for offprints should be addressed to W J Murdoch)
}

\begin{abstract}
Ovarian cells within the area of impending follicular rupture in the sheep exhibit evidence of DNA fragmentation. Most cells undergo a degenerative process indicative of apoptosis and are deleted before ovulation. However, some ovarian surface epithelial cells located along the margins of ruptured follicles persist (with damaged DNA) into the ensuing luteal phase. It is conceivable that a genetically-altered progenitor cell that has survived a sub-lethal insult at ovulation (i.e. with unrepaired DNA, but not committed to death) could give rise to a malignant phenotype that is propagated during the postovulatory ovarian surface wound-repair process. It was hypothesized that progesterone derived from the formative corpus luteum reestablishes genomic integrity among ovarian surface epithelial cells contiguous with the ovulatory site and that this response is mediated by the DNA repair/apoptosis-activating enzyme poly(ADP-ribose) polymerase (PARP). Ovarian surface epithelial cells immediately surrounding the ovulatory stigma of sheep follicles were recovered on luteal days 1, 2 or 4; control cells were obtained from an ipsilateral ovarian region removed from the point of ovulation. Immunofluorescent staining of end-linked digoxigenin or poly(ADP-ribose) was used to detect fragmented DNA or PARP-modified
\end{abstract}

proteins within individual cells. Approximately 25\% of surface epithelial cells that bordered the ovarian rupture site contained damaged DNA on days 1 and 2; there was a dramatic decrease by day $4(<5 \%)$. The decline in DNA-compromised cells was negated by in vivo inhibition of lutein progesterone production invoked by ovarian perivascular injection (day 1) of the $3 \beta$-hydroxysteroid dehydrogenase inhibitor isoxazol; this effect was reversed by exogenous progesterone. There was a positive relationship on day 2 between the level of ovarian progesterone and immunostaining of ADP-ribose polymers in surface epithelial cells associated with the ovulatory site. Evidence of DNA fragmentation or PARP activity in control cells was low and not affected by time of sample collection or treatments. The progesterone receptor antagonist RU486 and the transcriptional inhibitor actinomycin D blocked increases in PARP in ovarian surface epithelial cells incubated with progesterone. It is suggested that DNA damage to ovarian surface epithelium that is inflicted at ovulation is (normally) reconciled on a localized basis by progesterone/PARP-mediated repair or dedicated apoptotic cell death, thereby conferring protection against clonal transformation.

Journal of Endocrinology (1998) 156, 503-508

\section{Introduction}

The mammalian ovary is covered by a delicate layer of epithelium supported by a basal lamina (Anderson et al. 1976). A follicle selected to ovulate grows toward the ovarian perimeter, eventually coming into close contact with the surface epithelium. Ovarian epithelial cells that overlie the apical aspect of preovulatory ovine follicles become apoptotic (characterized by DNA fragmentation and pyknosis) and are sloughed with the approach of rupture (Ackerman \& Murdoch 1993, Murdoch 1994, 1995). The cellular void created along the ovarian surface is consequently mended by proliferative epithelium (Osterholzer et al. 1985, Gillett et al. 1991, Murdoch
1994). Inauspiciously, some cells at the margins of ruptured follicles, that endure after the ovulatory insult, contain fragmented DNA (Ackerman \& Murdoch 1993, Murdoch 1994, 1995). Damage to DNA left uncorrected could be problematic if hence propagated. Indeed, most ovarian cancers originate from surface epithelium that is traumatized at ovulation (Godwin et al. 1993, Murdoch 1996).

Poly(ADP-ribose) polymerase (PARP) plays an important role in the modification of chromatin structures adjacent to regions of DNA damage. Polymerization of ADP-ribose is accomplished by successive transfers of the ADP-ribosyl moiety of nicotinamide adenine dinucleotide (NAD) substrate. Catalytic automodification 
and poly-ADP-ribosylation have an absolute requirement for DNA strand breaks. Attachment of PARP to strand lesions and synthesis of (short-lived) branched polymers by the bound enzyme is rapid. Poly(ADP-ribose) synthesis in healthy cells is very low. It is generally assumed that adequate nuclear concentrations of PARP need to be maintained to ensure efficient recognition at random sites of DNA damage. It appears that PARP participates in two interrelated events, repair of damaged DNA (during cellular recovery) and the active phase of apoptosis (Lindahl et al. 1995).

The basic working premise of this investigation was that under normal circumstances the DNA repair and (or) apoptotic capacities of postovulatory ovarian surface epithelial cells (bearing DNA strand breaks) are enhanced by progesterone of local origin and that such a phenomenon is related to PARP activity. Impact of luteal progesterone status on the extent of DNA fragmentation and poly(ADP-ribose) accumulation among ovarian surface epithelial cells associated with the ovulatory site was assessed in the sheep. The direct effect of progesterone on induction of PARP in ovarian surface epithelium was evaluated under in vitro conditions.

\section{Materials and Methods}

\section{Experiment 1}

Mature Western-range ewes were penned daily with vasectomized rams and observed for estrous behavior. On day 14 of the estrous cycle, animals were injected i.m. with $10 \mathrm{mg}$ prostaglandin $\mathrm{F}_{2} \alpha$ tromethamine (Upjohn, Kalamazoo, MI, USA) to synchronize luteal regression. Five micrograms of a synthetic agonist of gonadotropinreleasing hormone (des $\mathrm{Gly}^{10}-\mathrm{Ala}^{6}$ ethylamide; $\mathrm{GnRH}$; Sigma, St Louis, MO, USA) were administered i.m. $36 \mathrm{~h}$ later to elicit a preovulatory surge of gonadotropins. Ovulation occurs approximately $24 \mathrm{~h}$ after injection of GnRH (Roberts et al. 1985).

Ovaries containing an ovulated follicle were removed when the animal was killed (i.v. Beuthanasia-D; ScheringPlough, Kenilworth, NJ, USA) on days 1, 2 or 4 of the luteal phase. Animals assigned to the day 2 and 4 groups received at laparotomy on day 1 an ovarian pedicle perivascular injection of $1 \mathrm{ml}$ corn oil (control) or vehicle containing $2 \mathrm{mg}$ isoxazol, $2 \mathrm{mg}$ progesterone or isoxazol+progesterone. Isoxazol (17 $\beta$-hydroxy-4,4, $17 \alpha$-tri-methylandrost-5-ene-(2,3d)-isoxazol; SterlingWinthrop, Rensselaer, NY, USA) is a specific inhibitor of $3 \beta$-hydroxysteroid dehydrogenase (Goldman \& Sheth 1973, Murdoch et al. 1986), an enzyme involved in the conversion of pregnenolone to progesterone (Miller 1988). It was inferred that the low molecular weight/lipophilic inhibitor and hormone would be delivered locally to the ovary in high concentrations by direct arterial absorption and countercurrent veno-arterial transfer (Ginther 1974,
Einer-Jensen 1988). Surgery was performed under general anesthesia (sodium thiopental i.v.) using aseptic technique. Four or five animals were included in each group. The experimental protocol was conducted with the approval of the University of Wyoming Animal Care and Use Committee.

Surface epithelial cells were removed from an area ( $\sim 4 \mathrm{~mm}$ wide) surrounding an ovulation stigma and from a distant site $(>12 \mathrm{~mm})$ on the same ovary using a teflon scraper (Becton Dickinson Co., Lincoln Park, NJ, USA) designed to detach adherent cells from culture flasks (that this technique efficiently recovered only surface epithelial cells was confirmed in a preliminary histological study). Postovulatory (lutein) follicles were dissected from ovaries, wet weights were recorded and tissues were analyzed for progesterone concentrations by radioimmunoassay (Murdoch \& Dunn 1982, Rahmanian \& Murdoch 1987). Ovarian surface epithelial cells were rinsed from the edge of the scraper with $0.1 \mathrm{ml}$ Histochoice fixative (Amresco, Solon, OH, USA) and transferred in equal aliquots onto subbed microscope slides (Davis et al. 1986) for respective single-cell analyses of DNA fragmentation and poly(ADP-ribose); slides were air-dried and washed in two changes of deionized water.

An Oncor (Gaithersburg, MD, USA) ApopTag S7111 kit was used to immunolabel fragmented DNA in permeabilized cells according to the detailed instructions of the manufacturer; this technique detects apoptotic cells with a $>10$-fold higher sensitivity than it does necrotic cells (Gorczyca et al. 1993). Briefly, exposed 3'-OH ends of DNA fragments were labeled with digoxigenin-11-d uridine triphosphate by terminal deoxynucleotidyl transferase (TdT) catalysis. Incorporated nucleotide heteropolymers were localized with antidigoxigenin Fab-fluorescein isothiocyanate (FITC). Conjugate or TdT were omitted in negative control reactions (using ovarian cells obtained from ewes that had more than one ovulation).

Poly(ADP-ribose) modified proteins were localized within ovarian surface epithelial cells by indirect immunofluorescence microscopy using a mouse monoclonal antibody (1:1000 dilution, $60 \mathrm{~min}$; BIOMOL, Plymouth Meeting, PA, USA) and secondary goat antimouse FITC-immunoglobulin G (1:64 dilution, $10 \mathrm{~min}$; Sigma). Samples were preincubated for $10 \mathrm{~min}$ in $10 \%$ normal goat serum. The primary antibody is not speciesspecific and does not cross-react with DNA, RNA, NAD or monomers of ADP-ribose. Negative control reactions were carried out in the absence of primary antibody and with primary antibody preadsorbed with poly(APDribose) protein (BIOMOL).

Cells were examined $(\times 400)$ under an Olympus $\mathrm{BH}-2$ microscope equipped with a reflected light fluorescence attachment. A random field representing a minimum of 30 cells per ovarian collection site for each assessment (fragmented DNA or ADP-ribose polymerization) was subjected to computer-assisted analysis 
(Optimas, Bothell, WA, USA). Defined images of individual cells were categorized as positively-labeled (luminance intensity $>2 \times$ control cell background) or not immunoreactive. A percent-response was calculated (immunopositive cells/total cells represented $\times 100$ ) for each field of investigation.

\section{Experiments 2-4}

Surface cells were recovered from ovaries (Ackerman \& Murdoch 1993) of ewe lambs slaughtered in the University of Wyoming Meat Science Abattoir. Pooled cells were suspended in Medium-199 (Sigma) and aliquoted $\left(2 \times 10^{6}\right)$ in 200- $\mu$ l increments into 24-well culture plates supplemented $(50 \mu \mathrm{l})$ with progesterone (final concentrations $=0,2 \cdot 5,5,10,20$ and $40 \mathrm{ng} / \mathrm{ml}$; Exp 2). Additional experiments were carried out in the absence or presence of progesterone $(0,20 \mathrm{ng} / \mathrm{ml})$, progesterone receptor antagonist RU486 (Cadepond et al. 1997, 0, $0 \cdot 2 \mu \mathrm{g} / \mathrm{ml}$; Exp 3), and(or) the transcriptional inhibitor actinomycin D (Sigma; 0, $0 \cdot 2 \mu \mathrm{g} / \mathrm{ml}$; Exp 4). Incubations were performed for $4 \mathrm{~h}$ at $37^{\circ} \mathrm{C}$. A minimum of six replicates were included in each treatment.

Cells were disrupted by sonication $(3 \times 10 \mathrm{~s}, 10 \mathrm{~W})$. Insoluble material was removed by microcentrifugation for $5 \mathrm{~min}$ at $3000 \mathrm{~g}$. Supernatants $(20 \mu \mathrm{g}$ crude protein) were assayed for PARP activity (incorporation of ${ }^{32} \mathrm{P}$ NAD into a TCA-precipitable polymer) using a validated kit according to the instructions of the manufacturer (Trevigen, Gaithersburg, MD, USA). Enzymatic reactions were carried out for $5 \mathrm{~min}$ at room temperature. Level of background was determined in the absence of cell extracts (average of six determinations). Coefficients of variation based on repeated measures $(n=5)$ of an ovarian surface cell extract pool and positive controls $(2 \mu \mathrm{g}$ PARP protein preparation) were $<8 \%$. Enzymatic activity of cell extracts $(n=6)$ was blocked (equivalent to background) by addition of $3 \mathrm{mM}$ 3-aminobenzamide, a non-toxic inhibitor of PARP (Milam \& Cleaver 1984).

\section{Statistical analyses}

Data were evaluated by analyses of variance. Mean contrasts were made using a protected least significant difference test. Differences were considered significant at $P<0 \cdot 05$. Standard errors of means are presented.

\section{Results}

\section{Experiment 1}

There was an increase $(P<0 \cdot 05)$ in weights of postovulatory follicles between days 2 and 4 of the luteal phase; this response was unaffected by treatment with isoxazol and(or) progesterone (106 \pm 7 vs $132 \pm 8 \mathrm{mg}$ ).

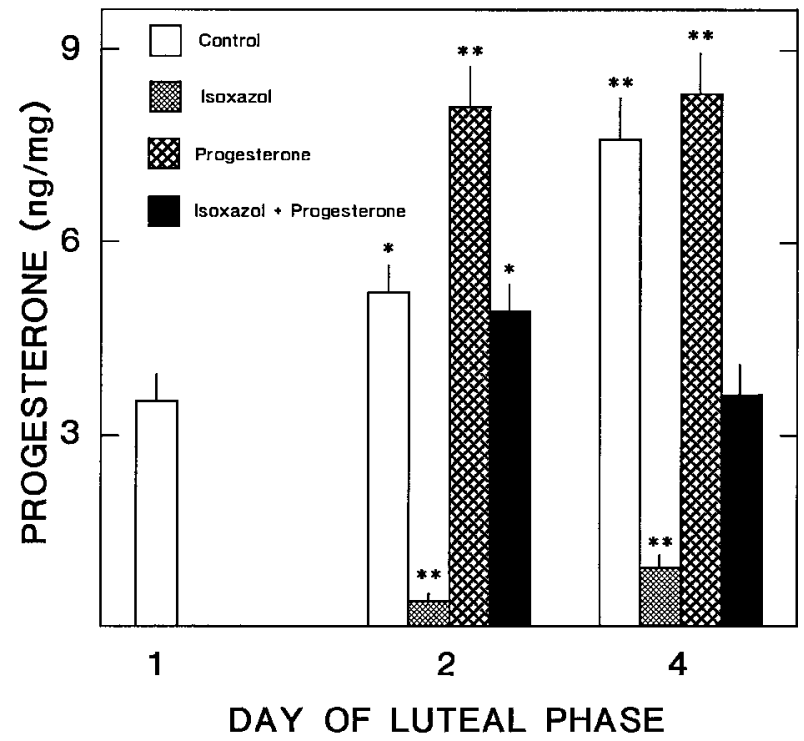

Figure 1 Postovulatory effects of isoxazol and(or) progesterone on folliculo-luteal concentrations of progesterone. Asterisks indicate differences $\left({ }^{*} P<0 \cdot 05 ;{ }^{* *} P<0 \cdot 001\right)$ from day 1 control.

Concentrations of progesterone within corpora lutea of control ewes increased linearly from day 1 through to day 4 . Treatment with isoxazol on day 1 caused a marked subsequent depression in tissue progesterone levels that was sustained through day 4 . Administration of progesterone with isoxazol restored luteal progesterone to nearnormal on day 2. Luteal progesterone on day 2 was elevated above the coincide control when hormone was given without isoxazol. Cumulative differential effects of exogenous progesterone were less pronounced by day 4 (Fig. 1).

Immunolabeling of fragmented DNA was evident in ovarian surface epithelial cells associated with the ovulatory site on days 1 and 2. There was a decline in immunopositive cells obtained from day 4 control, progesterone, and isoxazol+progesterone ovaries. An excess of cells with fragmented DNA was readily apparent on day 4 following treatment with isoxazol. Thus, the apparent persistence of DNA-damaged cells in the day 4 isoxazol only group was offset by progesterone replacement (>1 day exposure) therapy. Supplemental progesterone without isoxazol was of no added value, indicating that a critical (control) threshold of luteal progesterone concentrations had been attained (Fig. 2).

Accumulation of poly(ADP-ribose) in ovarian surface epithelial cells bordering postovulatory follicles was most conspicuous on day 2 in the presence of progesterone (vis-à-vis fragmented DNA); polymerization was inhibited by isoxazol. There were no significant differences due to treatments in poly(ADP-ribose) detection on day 4 (Fig. 3). 


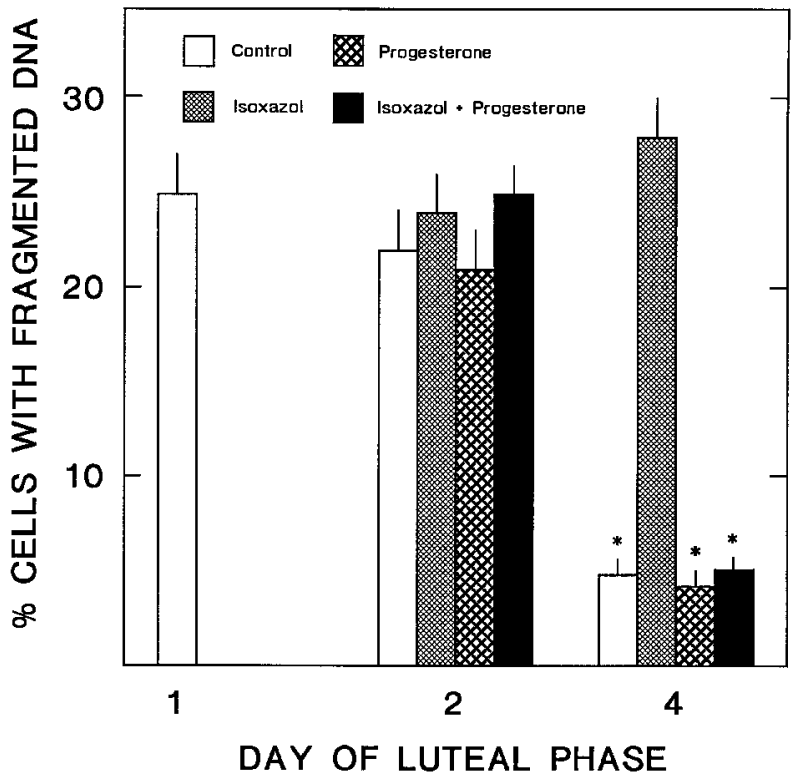

Figure 2 Temporal effects of isoxazol and(or) progesterone on detection of fragmented DNA in ovarian surface epithelial cells associated with the ovulatory site. Asterisks denote differences $(P<0 \cdot 001)$ from other means.

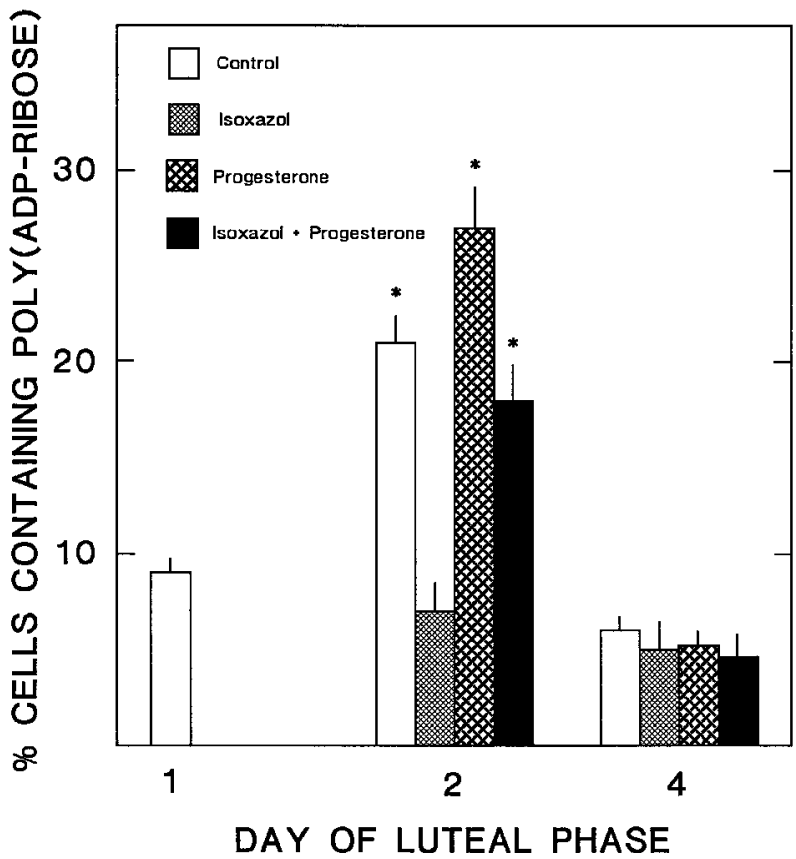

Figure 3 Temporal effects of isoxazol and(or) progesterone on detection of poly(ADP-ribose) in ovarian surface epithelial cells associated with the ovulatory site. Asterisks denote differences $(P<0 \cdot 001)$ from other means.

Presumptive alterations to chromatin structure were confined to ovarian surface epithelial cells recovered from contiguous areas of follicular rupture. Discerned instances of DNA fragmentation and poly(ADP-ribose) accumulation within surface epithelial cells removed from ovarian sites peripheral to ovulation papillae were considered baseline $(<6 \%)$ and were not altered by time of sample collection or treatments.

Experiments 2-4

Relative PARP activity of isolated ovarian surface epithelial cells was enhanced in a dose-response manner by the addition of progesterone to incubation medium. The hormone-induced increase in PARP was negated by coincident treatment with RU486 or actinomycin D (Fig. 4).

\section{Discussion}

Results of the in vivo study indicate that progesterone of luteal origin is involved in the restoration and(or) demise of ovarian surface epithelial cells containing DNA that had been damaged during the ovulatory process; circumstantial evidence indicates that PARP could mediate such effects. As expected, polymerization of ADP-ribose was related to DNA fragmentation.

Results of the in vitro experiments indicate that the stimulatory effect of progesterone on PARP in ovarian surface epithelium is receptor-mediated and exerted at the transcriptional level, typical of steroid hormone actions in general (Truss \& Beato 1993). Progesterone receptors have been localized within ovarian surface epithelial cells (Rao \& Slotman 1991). Little is known regarding mechanisms that control constitutive expression of PARP. Strand interruptions in DNA are apparently not necessary for induction of the gene that encodes PARP (Bhatia et al. 1990). In vitro doses of progesterone required to augment PARP bioactivity within ovarian surface epithelial cells exceeded those characteristic of the systemic circulation (Murdoch 1994); this is interpreted to imply that sufficient amounts of progesterone are delivered in situ to surface cells by simple diffusion from the developmental corpus luteum.

The precise role of PARP in DNA repair remains equivocal (Lindahl et al. 1995). Outcome might be contingent upon extent of damage. In cases of mild injury, PARP may serve as an adjunct to aid in efficiency of DNA repair. It is possible that binding of PARP in areas of DNA strand breaks elicits a signal that restrains DNA replication (Kaufmann \& Paules 1996) until ADP-ribose polymer disassembly, PARP dissociation, and DNA repair is complete (Satoh \& Lindahl 1992). If repair is futile (irrevocable damage), then PARP (possibly via NAD depletion) condemns precarious cells to apoptotic death (Nosseri et al. 1994). Cleavage of PARP by an interleukin-1 $\beta$-like converting protease has been implicated in the execution (endonuclease-potentiated) phase of apoptosis (Lazebnik 


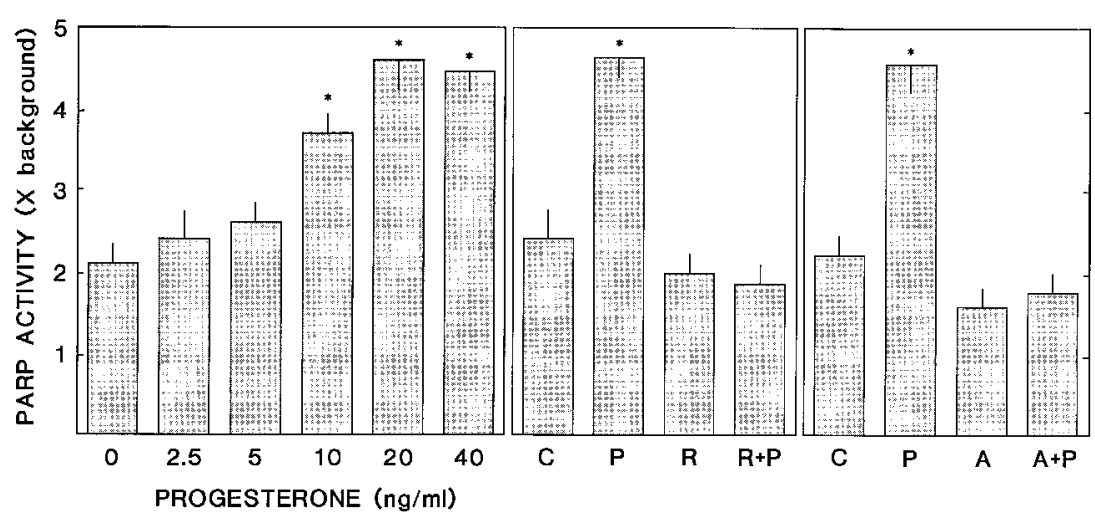

Figure 4 In vitro effects of progesterone (P, $20 \mathrm{ng} / \mathrm{ml})$, RU486 (R), and(or) actinomycin D (A) on PARP activity of sheep ovarian surface epithelial cells. Asterisks indicate differences $(P<0.01)$ from control $(\mathrm{C}, 0 \mathrm{ng} / \mathrm{ml}$ progesterone).

et al. 1995, Umansky 1996). Regardless of the obligate mode of action, accurate repair or proficient removal of damaged cells is essential to prevent accumulation of potentially harmful mutations.

Although the surface epithelium represents only a diminutive fraction of the diverse cell-types that comprise the ovary, it accounts for over $90 \%$ of all cancers attributed to this complex organ. It appears that the first step in tumorigenesis involves disturbances to the ovarian surface stemming from ovulation and that repetitious ovulation is a decisive factor in the etiology of ovarian neoplasia. In fact, situations that avert ovulation (e.g. oral contraceptive use and pregnancy) afford significant protection against the development of epithelial ovarian cancer (Godwin et al. 1993). The endogenous counter to the ovulatory affront is apparently sustained by progesterone.

That sex steroid hormones can augment mechanisms of DNA damage processing within reproductive tissues is of fundamental pathophysiological importance. It is possible that steroid hormones can act to enhance mechanisms that assure genomic fidelity in other endocrine paradigms that involve dynamic remodeling of tissues (e.g. uterus, mammary gland, prostate gland). Unfortunately, a hormonal propensity to inhibit apoptosis and(or) enhance DNA repair mechanisms in stable transformed cancer cells would almost certainly be a liability (i.e. as an untoward promoter of tumor progression and drug resistance). Experiments are underway to determine if gonadal steroids can alter the in vitro survival rate and DNA repair capabilities of human ovarian cancer cells of epithelial origin.

\section{Acknowledgements}

This work was supported by USDA grant no. 95-372032131. Assistance provided by R Ackerman, G Johnson and $\mathrm{C}$ Huitt with animal surgery and by E Van Kirk for tissue progesterone analysis is gratefully acknowledged. Mifepristone (NIMH Chemical Synthesis Program) was donated by Research Biochemicals International, Natrick, MA, USA.

\section{References}

Ackerman RC \& Murdoch WJ 1993 Prostaglandin-induced apoptosis of ovarian surface epithelial cells. Prostaglandins $\mathbf{4 5}$ 473-483.

Anderson E, Lee G, Letourneau R, Albertini DF \& Meller SM 1976 Cytological observations of the ovarian epithelium in mammals during the reproductive cycle. Journal of Morphology 150 135-166.

Bhatia K, Pommier Y, Giri C, Fornace AJ, Imaizumi M, Breitman TR, Cherney BW \& Smulson ME 1990 Expression of the poly(ADP-ribose) polymerase gene following natural and induced DNA strand breakage and effect of hyperexpression on DNA repair. Carcinogenesis 11 123-128.

Cadepond F, Ulmann A \& Baulieu EE 1997 RU486 (Mifepristone): mechanisms of action and clinical uses. Annual Review of Medicine 48 129-156.

Davis LG, Dibner MD \& Battey JF 1986 Basic Methods in Molecular Biology, p 357. New York: Elsevier Science Publishing Co. Inc.

Einer-Jensen N 1988 Countercurrent transfer in the ovarian pedicle and its physiological implications. Oxford Reviews of Reproductive Biology 10 348-381.

Gillett WR, Mitchell A \& Hurst PR 1991 A scanning electron microscopic study of the human ovarian surface: characterization of two cell types. Human Reproduction 6 645-650.

Ginther OJ 1974 Internal regulation of physiological processes through local venoarterial pathways: a review. Journal of Animal Science 39 550-564.

Godwin AK, Testa JR \& Hamilton TC 1993 The biology of ovarian cancer development. Cancer 71 530-536.

Goldman AS \& Sheth K 1973 Inhibitors of human placental $C_{19}$ and $\mathrm{C}_{21}$ 3ß-hydroxysteroid dehydrogenases. Biochimica et Biophysica Acta $315233-249$.

Gorczyca W, Bigman K, Mittelman A, Ahmed T, Gong J, Melamed MR \& Darzynkiewicz Z 1993 Induction of DNA strand breaks associated with apoptosis during treatment of leukemias. Leukemia 7 659-670.

Kaufmann WK \& Paules RS 1996 DNA damage and cell cycle checkpoints. FASEB Journal 10 238-247. 
Lazebnik YA, Takahashi A, Poirer SH, Kaufmann SH \& Earnshaw WC 1995 Characterization of the execution phase of apoptosis in vitro using extracts from condemned-phase cells. Journal of Cell Science 19 41-49.

Lindahl T, Satoh MS, Poirier GG \& Klungland A 1995 Posttranslational modification of poly(ADP-ribose) polymerase induced by DNA strand breaks. Trends in Biochemical Sciences $\mathbf{2 0}$ 405-411.

Milam KM \& Cleaver JE 1984 Inhibitors of poly(adenosine diphosphate-ribose) synthesis: effect on other metabolic processes. Science 223 589-591.

Miller WL 1988 Molecular biology of steroid hormone synthesis. Endocrine Reviews 9 295-318.

Murdoch WJ 1994 Ovarian surface epithelium during ovulatory and anovulatory ovine estrous cycles. Anatomical Record $\mathbf{2 4 0}$ 322-326.

Murdoch WJ 1995 Programmed cell death in preovulatory ovine follicles. Biology of Reproduction 53 8-12.

Murdoch WJ 1996 Ovarian surface epithelium, ovulation, and carcinogenesis. Biological Reviews 71 529-543.

Murdoch WJ \& Dunn TG 1982 Alterations in follicular steroid hormones during the preovulatory period in the ewe. Biology of Reproduction 27 300-307.

Murdoch WJ, Peterson TA, Van Kirk EA, Vincent DL \& Inskeep EK 1986 Interactive roles of progesterone, prostaglandins and collagenase in the ovulatory mechanism of the ewe. Biology of Reproduction $\mathbf{3 5}$ 1187-1194.
Nosseri C, Coppola S \& Ghibelli L 1994 Possible involvement of poly(ADP-ribose) polymerase in triggering stress-induced apoptosis. Experimental Cell Research 212 367-373.

Osterholzer HO, Johnson JH \& Nicosia SV 1985 An autoradiographic study of the rabbit ovarian surface epithelium before and after ovulation. Biology of Reproduction 33 729-738.

Rahmanian MS \& Murdoch WJ 1987 Function of ovine corpora lutea after administration of luteinizing hormone-releasing hormone. Journal of Animal Science 64 648-655.

Rao BR \& Slotman BJ 1991 Endocrine factors in common epithelial cancer. Endocrine Reviews 12 14-26.

Roberts AJ, Dunn TG \& Murdoch WJ 1985 Induction of ovulation in proestrous ewes: identification of the ovulatory follicle and functional status of the corpus luteum. Domestic Animal Endocrinology 2 207-210

Satoh MS \& Lindahl T 1992 Role of poly(ADP-ribose) formation in DNA repair. Nature 356 356-358.

Truss M \& Beato M 1993 Steroid hormone receptors: interaction with deoxyribonucleic acid and transcription factors. Endocrine Reviews $\mathbf{1 4}$ 459-479.

Umansky SR 1996 Apoptosis: molecular and cellular mechanisms. Molecular Biology 30 285-295.

Received 1 April 1997

Revised manuscript received 28 August 1997

Accepted 9 October 1997 